\title{
The Predictive Value of Integrated Pulmonary Index after Off-Pump Coronary Artery Bypass Grafting: A Prospective Observational Study
}

\author{
Evgenia V. Fot', Natalia N. Izotova, Anjelika S. Yudina, Aleksei A. Smetkin, \\ Vsevolod V. Kuzkov and Mikhail Y. Kirov
}

Department of Anesthesiology and Intensive Care Medicine, Northern State Medical University, Arkhangelsk, Russia

Background: The early warning scores may increase the safety of perioperative period. The objective of this study was to assess the diagnostic and predictive role of Integrated Pulmonary Index (IPI) after off-pump coronary artery bypass grafting (OPCAB).

\section{OPEN ACCESS}

Edited by:

Bernd Saugel,

University Medical Center Hamburg-

Eppendorf, Germany

Reviewed by:

Agnes S. Meidert,

Ludwig-Maximilians-Universität

München, Germany

Daniel Lahner,

Institute for Experimental and Clinical

Traumatology (LBG), Austria

${ }^{*}$ Correspondence:

Evgenia V. Fot

ev_fot@mail.ru

Specialty section: This article was submitted to Intensive Care Medicine and Anesthesiology,

a section of the journal

Frontiers in Medicine

Received: 14 June 2017

Accepted: 25 July 2017

Published: 09 August 2017

Citation:

Fot EV, Izotova NN, Yudina AS, Smetkin AA, Kuzkov W and Kirov MY

(2017) The Predictive Value of Integrated Pulmonary Index after

Off-Pump Coronary Artery Bypass

Grafting: A Prospective

Observational Study.

Front. Med. 4:132.

doi: 10.3389/fmed.2017.00132
Materials and Methods: Forty adult patients undergoing elective OPCAB were enrolled into a single-center prospective observational study. We assessed respiratory function using IPI that includes oxygen saturation, end-tidal $\mathrm{CO}_{2}$, respiratory rate, and pulse rate. In addition, we evaluated blood gas analyses and hemodynamics, including ECG, invasive arterial pressure, and cardiac index. The measurements were performed after transfer to the intensive care unit, after spontaneous breathing trial and at 2, 6, 12, and $18 \mathrm{~h}$ after extubation.

Results and Discussion: The value of IPI registered during respiratory support correlated weakly with cardiac index ( $\mathrm{rho}=0.4 ; p=0.04)$ and $\mathrm{ScvO}_{2}(\mathrm{rho}=0.4, p=0.02)$. After extubation, IPI values decreased significantly, achieving a minimum by $18 \mathrm{~h}$. The $\mathrm{IPI}$ value $\leq 9$ at $6 \mathrm{~h}$ after extubation was a predictor of complicated early postoperative period (AUC $=0.71 ; p=0.04$ ) observed in 13 patients.

Conclusion: In off-pump coronary surgery, the IPI decreases significantly after tracheal extubation and may predict postoperative complications.

Keywords: postoperative respiratory failure, coronary artery bypass grafting, monitoring, microstream capnography, integrated pulmonary index

\section{INTRODUCTION}

Cardiac surgery can be complicated by respiratory failure that may contribute to increased morbidity and additional health-care costs $(1,2)$. The outcome of coronary artery bypass grafting can be significantly influenced by decompensation caused by chronic pulmonary diseases and other complications (atelectases, pleuritis, etc.) (3-5). Therefore, the thorough postoperative monitoring of pulmonary function during both mechanical ventilation and spontaneous breathing may be of a great value. Notably, the modern monitoring devices should be accurate and non- or minimally invasive with measurements that are continuous and results easily interpreted (6).

To maintain respiratory function, the cardiosurgical patients are monitored using pulse oximetry, capnography, respiratory rate, and discrete blood gas analysis (7-9). Although blood gas analyses are the gold standard for early detection of different types of respiratory failure, they are invasive, 
cannot be measured continuously, and frequently impose a delay between sampling and availability of results (10). Thus, the early warning systems allowing early recognition of critical respiratory events might be of value when patient is monitored both in the intensive care unit (ICU), postoperative ward, and high dependency unit. This approach can be particularly useful with a limited number of medical staff. Several observational studies indicate that early warning systems improve detection of complications (11), and their use is recommended by the World Federation of Societies of Anesthesiologists to facilitate the work of nurses and physicians in the ICU $(12,13)$.

The Integrated Pulmonary Index (IPI) is an automated value calculated by one monitor (Capnostream-20, Medtronic, Israel) and can be considered as an automated early warning system. The IPI algorithm utilizes the real time measures and interactions of four parameters-end-tidal $\mathrm{CO}_{2}\left(\mathrm{PetCO}_{2}\right)$, respiration rate, pulse rate, and oxygen saturation $\left(\mathrm{SpO}_{2}\right)$ to provide an assessment of the patient's respiratory status. The calculation of the IPI is based on the fuzzy logic principle, a mathematical model, which mimics human logic thinking; detailed description of the algorithm was provided by Ronen et al. (14) The values of IPI below 7 have been suggested to be an indicator for respiratory deterioration (14).

Currently, only few investigations of IPI were performed during non-cardiosurgical procedures (14-18) In these studies, IPI algorithm correlated with the respiratory status and has demonstrated the ability for promoting early awareness to changes in a patient's respiratory system.

The aim of our study was to assess the diagnostic and predictive role of IPI during the discontinuation from mechanical ventilation and in the early postextubation period after off-pump coronary artery bypass grafting (OPCAB).

\section{MATERIALS AND METHODS}

The study was performed in a 900-bed university hospital (City Hospital \# 1 of Arkhangelsk, Russia). During 2015, 40 adult patients undergoing elective OPCAB were enrolled into an observational prospective study. The study design and the informed consent form were approved by the Ethical Committee of Northern State Medical University (Arkhangelsk, Russian Federation) and registered with http://ClinicalTrials.gov (ref: NCT02524522). Written informed consent was obtained from every patient. Exclusion criteria were age $<18$ and $>80$ years, morbid obesity with body mass index $>40 \mathrm{~kg} / \mathrm{m}^{2}$, and constant atrial fibrillation.

All patients were intubated using the standard induction technique with sodium thiopental $(4 \mathrm{mg} / \mathrm{kg})$, fentanyl $(2.5-3.0 \mu \mathrm{g} / \mathrm{kg})$ and pipecuronium bromide $(0.1 \mathrm{mg} / \mathrm{kg})$. Anesthesia was maintained using sevoflurane (0.5-3.0 vol.\% at the end of expiration) and fentanyl $(2.0-4.0 \mu \mathrm{g} / \mathrm{kg} / \mathrm{h})$. Depth of anesthesia was adjusted to maintain BIS values between 40 and 60 (LifeScope, Nihon Kohden, Japan).

In all cases, preoxygenation with $80 \% \mathrm{O}_{2}$ was provided during 3-5 min before anesthesia. After tracheal intubation, patients were ventilated using a protective volume-controlled mode (Dräger Primus, Germany) with tidal volume of $6-8 \mathrm{~mL} / \mathrm{kg}$ of predicted body weight, flow of $1 \mathrm{~L} / \mathrm{min}$ and positive end-expiratory pressure (PEEP) of $5 \mathrm{~cm} \mathrm{H}_{2} \mathrm{O} . \mathrm{FiO}_{2}$ was set to at least $50 \%$ or higher to achieve intraoperative $\mathrm{SpO}_{2}$ above $95 \%$. The respiratory rate was adjusted to maintain $\mathrm{PetCO}_{2}$ value within $30-35 \mathrm{mmHg}$.

After surgery, all patients were transferred to the postoperative cardiac ICU and shortly sedated with continuous infusion of propofol $(2-4 \mu \mathrm{g} / \mathrm{kg} / \mathrm{h})$ to maintain BIS values within $60-70$. Respiratory support in ICU was provided by a G5 ventilator (Hamilton Medical, Switzerland) using pressure controlled ventilation mode with parameters of intraoperative ventilation. Additionally, all patients received recruitment maneuver by raising the PEEP to $20 \mathrm{~cm} \mathrm{H}_{2} \mathrm{O}$ for $5 \mathrm{~min}$.

After the initial measurements, sedation was stopped, and the weaning from respiratory support was initiated. The weaning protocol included gradual reduction of inspiratory pressure and mandatory respiratory rate, as well as spontaneous breathing trial. After passing the 30-min spontaneous breathing trial, all the patients were immediately extubated. After extubation, the patients received a supplementary oxygen flow of $4 \mathrm{~L} / \mathrm{min}$ via a nasal catheter. During the weaning process and in the early postextubation period, all the patients received continuous infusion of fentanyl and discrete administration of paracetamol for multimodal analgesia. In addition, the postoperative therapy included aspirin, low-molecular weight heparins, and bisoprolol.

The measurements included ventilator parameters, blood gas analyses (ABL800Flex, Radiometer, Denmark), $\mathrm{PetCO}_{2}, \mathrm{SpO}_{2}$, respiratory rate, pulse rate, and IPI (Capnostream-20, Medtronic). The IPI measurement is based on continuous transformation of $\mathrm{SpO}_{2}, \mathrm{PetCO}_{2}$, pulse rate, and respiratory rate values into a single index from 1 to 10 , where " 10 " indicates a normal respiratory status, and " 1 " indicates that patient requires immediate intervention. We distributed patients into two subgroups: with optimal (IPI 9-10) and suboptimal (IPI $\leq 8$ ) IPI values (Table 1). After tracheal extubation, for a more accurate assessment of the IPI, all the values were measured following breathing during $5 \mathrm{~min}$ without supplemental oxygen $\left(\mathrm{FiO}_{2}\right.$ 0.21), avoiding the reduction of $\mathrm{SpO}_{2}$ less than $88 \%$. Continuous hemodynamic measurements included ECG monitoring, invasive arterial pressure and cardiac output measured with pulse wave transit time (esCCO, Nihon Kohden, Japan).

All these parameters were registered after transfer to the ICU, as well as after spontaneous breathing trial and at 2, 6, 12, and $18 \mathrm{~h}$ after extubation. In addition, we recorded the preoperative EuroScore II, perioperative fluid balance, left ventricle ejection fraction assessed by transthoracic echocardiography before and $24 \mathrm{~h}$ after surgery, duration of postoperative mechanical ventilation and ICU stay, as well as early postoperative complications and hospitalization time. Postoperative complications were assessed according to the categories as predefined the study protocol: arrhythmias, hemorrhage, respiratory complications,

TABLE 1 | The clinical interpretation of Integrated Pulmonary Index (IPI) (14).

\begin{tabular}{lll}
\hline IPI & Patient status & Subgroups \\
\hline $10-9$ & Normal & Optimal values \\
8 & Within normal range & Suboptimal values \\
7 & Close to normal range; requires attention & \\
$5-6$ & Requires attention and may require intervention & \\
3 & Requires intervention & \\
$1-2$ & Requires immediate intervention &
\end{tabular}


neurological complications, and postoperative myocardial damage. Arrhythmic complications were comprised of any episode of atrial fibrillation, ventricular arrhythmia, or fibrillation requiring therapeutic intervention. Hemorrhagic complications were defined as drainage blood loss of more than $200 \mathrm{~mL} / \mathrm{h}$ for three consecutive hours or re-sternotomy. Respiratory complications were reintubation, need for prolonged oxygen therapy, pneumothorax, hydrothorax, chylothorax, or pneumonia. Patients were considered as requiring prolonged oxygen therapy after extubation in case if needed oxygen insufflation more than $12 \mathrm{~h}$ to maintain $\mathrm{SpO}_{2}>93 \%$. Neurological complications were defined as postoperative delirium or stroke. The postoperative myocardial damage was defined as an increase in the plasma concentration of creatine kinase-MB $>50 \mathrm{pg} / \mathrm{mL}$.

\section{Statistical Analysis}

For data collection and analysis, we used SPSS software (version 17.0; SPSS Inc., USA) and MedCalc software (version 12.3, MedCalc Software, Belgium). Due to pilot design of the study, the sample size was limited by 40 patients. All the variables were expressed as median $\left(25^{\text {th }}-75^{\text {th }}\right.$ interquartile interval $)$. The groups were compared using Mann-Whitney test. The intragroup comparisons were performed by Friedman and post hoc Wilcoxon tests with Bonferroni correction. For correlation analysis, we used Spearman test. Nominal data were compared using $\chi^{2}$ test and expressed as patient number. To evaluate the ability of IPI and $\mathrm{PetCO}_{2}$ to predict cardiac index $<2.5 \mathrm{~L} / \mathrm{min} / \mathrm{m}^{2}$ during mechanical ventilation, we performed ROC-curve analysis and calculated area under the ROC curve (AUC). The ROC analysis was also used to assess the capability of IPI and $\mathrm{PaO}_{2} / \mathrm{FiO}_{2}$ measured at $6 \mathrm{~h}$ after extubation for prediction of postoperative complications during $24 \mathrm{~h}$. The optimal cutoff point for IPI was determined by maximum value of the Youden Index (maximizing sensitivity and specificity). For post hoc intragroup comparisons, $p$ value $<0.013$ was considered as statistically significant. In all other cases, $p$ value $<0.05$ was regarded as statistically significant.

\section{RESULTS}

We enrolled 30 males and 10 females. Demographic and baseline characteristics of the patients, as well as postoperative complications are shown in Table 2.

After admission to the ICU, we had difficulties in registration of the IPI value only in one patient. Notably, $10 \mathrm{~min}$ later IPI was registered in $100 \%$ of patients. After admission to the ICU, $5 \%$ of patients required attention according to their respiratory status and had IPI $<7$. Simultaneously, $63 \%$ of patients had $\mathrm{PaO}_{2} / \mathrm{FiO}_{2}<300 \mathrm{mmHg}$. The IPI values, measured after ICU admission, weakly correlated with cardiac index (rho $=0.4$, $p=0.04)$ and $\mathrm{ScvO}_{2}($ rho $=0.4, p=0.02)$. The decreased values of IPI and $\mathrm{PetCO}_{2}$ during controlled mechanical ventilation were associated with $\mathrm{CI}<2.5 \mathrm{~L} / \mathrm{min} / \mathrm{m}^{2}$ (cutoff point for IPI $\leq 8$, sensitivity $84 \%$, specificity $53 \%$, positive predictive value $64 \%$, negative predictive value $75 \%, \mathrm{AUC}=0.72, p=0.02$; cutoff point for $\mathrm{PetCO}_{2} \leq 30 \mathrm{mmHg}$, sensitivity $78 \%$, specificity $68 \%$, positive predictive value $70 \%$, negative predictive value $76 \%, \mathrm{AUC}=0.73$, $p=0.02$, Figure 1).
TABLE 2 | The patient characteristics during perioperative period.

\begin{tabular}{|c|c|}
\hline Characteristics & Value \\
\hline Age, years & $62(55-70)$ \\
\hline $\mathrm{BMI}, \mathrm{kg} / \mathrm{m}^{2}$ & $30(27-31)$ \\
\hline EuroScore II, points & $1.15(0.85-1.59)$ \\
\hline Duration of surgery, min & $210(185-250)$ \\
\hline Grafts, number & $3(2-4)$ \\
\hline Intraoperative fluid balance, $\mathrm{mL}$ & $900(563-1,238)$ \\
\hline \multicolumn{2}{|c|}{ Baseline characteristics after admission to the ICU } \\
\hline IPI & $9(8-10)^{a}$ \\
\hline $\mathrm{PaO}_{2} / \mathrm{FiO}_{2}, \mathrm{mmHg}$ & $270(193-332)$ \\
\hline $\mathrm{SpO}_{2}, \%$ & $100(98-100)$ \\
\hline $\mathrm{PetCO}_{2}, \mathrm{mmHg}$ & $30(28-34)$ \\
\hline $\mathrm{PR}, \mathrm{bpm}$ & $61(54-75)$ \\
\hline $\mathrm{RR} / \mathrm{min}$ & $15(13-15)$ \\
\hline $\mathrm{PaCO}_{2}, \mathrm{mmHg}$ & $39(36-41)$ \\
\hline Cardiac index, L/min/m² & $2.41(2.04-2.76)$ \\
\hline Duration of postoperative ventilation, min & $193(138-258)$ \\
\hline Duration of ICU stay, h & $24(24-66)$ \\
\hline \multicolumn{2}{|l|}{ Postoperative complications ( $n=13$ ) } \\
\hline Arrhythmia & 5 \\
\hline Respiratory complications & 6 \\
\hline Hemorrhagic complications & 1 \\
\hline Neurological complications & 1 \\
\hline Myocardial damage & 0 \\
\hline
\end{tabular}

${ }^{2} n=39 ;$ in all other cases $n=40$.

Data presented as median (25th-75th percentile), percentage or numbers.

$B M I$, body mass index; PR, pulse rate; $R R$, respiratory rate; ICU, intensive care unit; IPI, Integrated Pulmonary Index.

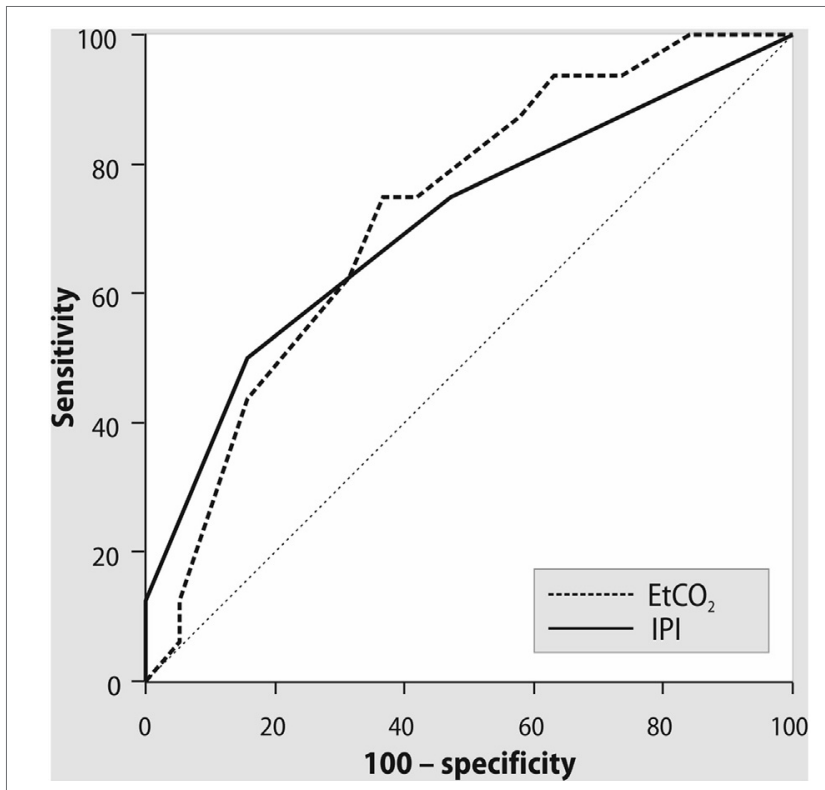

FIGURE 1 | ROC curves for Integrated Pulmonary Index (IPI), end-tidal $\mathrm{CO}_{2}$, and cardiac index $<2.5 \mathrm{~L} / \mathrm{min} / \mathrm{m}^{2}$ during mechanical ventilation. $\mathrm{AUC}=0.72$, $p=0.02$; cutoff point of IPI $\leq 8$, with sensitivity $84 \%$, specificity $53 \%$, positive predictive value $64 \%$, negative predictive value $75 \%$. AUC $=0.73, p=0.02$; cutoff point of $\mathrm{PetCO}_{2} \leq 30 \mathrm{mmHg}$, with sensitivity $78 \%$, specificity $68 \%$, positive predictive value $70 \%$, negative predictive value $76 \%$.

All patients were successfully weaned from mechanical ventilation. $\mathrm{PaO}_{2} / \mathrm{FiO}_{2}$ ratio was stable both during the spontaneous breathing trial and after tracheal extubation. In contrast, IPI 


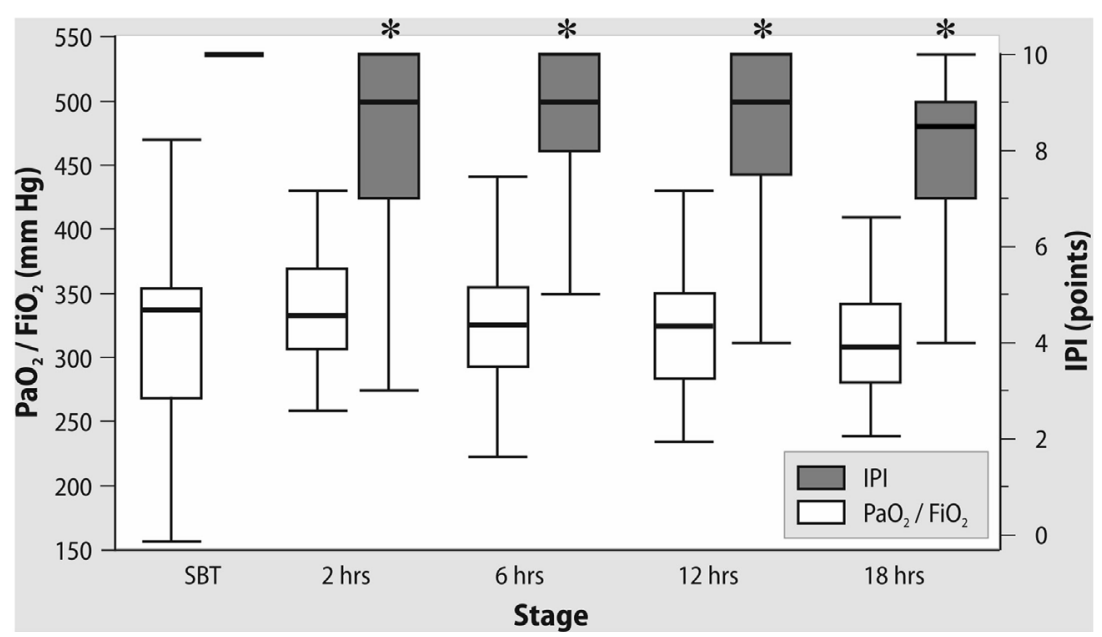

FIGURE 2 | Changes in $\mathrm{PaO}_{2} / \mathrm{FiO}_{2}$ and Integrated Pulmonary Index (IPI) after tracheal extubation. *Wilcoxon test, $p<0.01$.

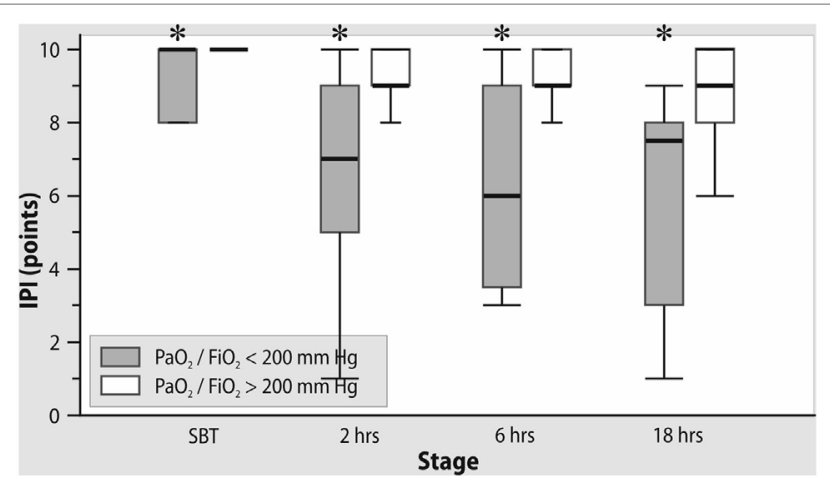

FIGURE 3 | The changes in Integrated Pulmonary Index (IPI) after extubation in subgroups with $\mathrm{PaO}_{2} / \mathrm{FiO}_{2}<200 \mathrm{mmHg}$ and $>200 \mathrm{mmHg}$ on admission to the intensive care unit. *Mann-Whitney test, $p<0.05$.

decreased significantly after OPCAB with a minimal value at $18 \mathrm{~h}$ after extubation (Figure 2). As shown in Figure 3, in patients with $\mathrm{PaO}_{2} / \mathrm{FiO}_{2}<200 \mathrm{mmHg}$ on ICU admission, the IPI values at 2 , 6,12 , and $18 \mathrm{~h}$ after extubation did not exceed suboptimal range $(\leq 8)(p<0.05$ as compared to IPI values of the subgroup with $\mathrm{PaO}_{2} / \mathrm{FiO}_{2}>200 \mathrm{mmHg}$ ).

In addition, the suboptimal IPI values at $2 \mathrm{~h}$ after tracheal extubation were associated with higher preoperative EuroScore and decreased left ventricular ejection fraction before and after OPCAB (Table 3). In the subgroup with IPI $\leq 8$, we observed decreased $\mathrm{SpO}_{2}$ and etCO , as well as increased pulse rate. Higher IPI values were associated with positive fluid balance and decreased rate of diuretic administration at the first day of ICU stay.

The length of ICU and hospital stay did not differ between the patients with optimal and suboptimal IPI values. We did not find any associations between $\mathrm{PaO}_{2} / \mathrm{FiO}_{2}$ ratio and the length of ICU stay either. However, IPI value $\leq 9$ at $6 \mathrm{~h}$ after extubation demonstrated moderate predictive ability for early postoperative complications $(\mathrm{AUC}=0.707 ; p=0.04$, with sensitivity $92 \%$ and specificity $48 \%$, positive predictive value $57 \%$, negative predictive
TABLE 3 | Comparative characteristics in subgroups of patients with optimal $(>8)$ and suboptimal $(\leq 8) \mathrm{IPI}$ values at $2 \mathrm{~h}$ after extubation.

\begin{tabular}{|c|c|c|c|}
\hline Characteristics & $\mathrm{IPI}_{\text {optimal }}(n=25)$ & $\mathrm{IPI}_{\text {suboptimal }}(n=13)$ & $p$-Value \\
\hline Age, years & $63(55-70)$ & $65(56-74)$ & 0.69 \\
\hline $\mathrm{BMl}, \mathrm{kg} / \mathrm{m}^{2}$ & $29(27-32)$ & $30(28-32)$ & 0.63 \\
\hline EuroScore II, points & $1.01(0.84-1.5)$ & $1.4(1.2-2.05)^{\mathrm{a}}$ & 0.03 \\
\hline EF before surgery, \% & $60(55-66)$ & $52(46-60)^{a}$ & 0.02 \\
\hline EF after surgery, \% & $63(60-68)$ & $57(52-62)^{a}$ & 0.007 \\
\hline $\mathrm{SpO}_{2}, \%$ & 95 (93-98) & $93(89-95)^{a}$ & 0.045 \\
\hline $\mathrm{etCO}_{2}, \mathrm{mmHg}$ & 37 (35-39) & $33(30-35)^{a}$ & 0.03 \\
\hline $\mathrm{PR}, \mathrm{bpm}$ & 77 (70-88) & $88(75-99)^{a}$ & 0.04 \\
\hline $\mathrm{RR} / \mathrm{min}$ & $14(14-18)$ & $15(15-18)$ & 0.33 \\
\hline $\mathrm{PaO}_{2} / \mathrm{FiO}_{2}, \mathrm{mmHg}$ & 324 (301-349) & 317 (293-331) & 0.32 \\
\hline $\mathrm{PaCO} 2, \mathrm{mmHg}$ & 38 (36-39) & $36(31-39)$ & 0.58 \\
\hline Fluid balance, $\mathrm{mL}$ & $320(-110$ to 498$)$ & $-225(-337 \text { to }+275)^{a}$ & 0.03 \\
\hline Urine output, $\mathrm{mL} / \mathrm{kg} / \mathrm{h}$ & $1.0(0.7-1.3)$ & $1.2(1.0-1.6)$ & 0.06 \\
\hline Administration of diuretics & 4 & $11^{\mathrm{b}}$ & 0.05 \\
\hline Duration of surgery, min & 195 (172-237) & 245 (202-255) & 0.13 \\
\hline Duration of ICU stay, h & $24(24-72)$ & $24(24-48)$ & 0.30 \\
\hline Hospitalization time, days & $9(7-10)$ & $9(8-12)$ & 0.35 \\
\hline
\end{tabular}

Data presented as median (25th-75th percentile), percentage or numbers.

$B M I$, body mass index; EF, ejection fraction; PR, pulse rate; $R R$, respiratory rate; ICU, intensive care unit.

Bold font indicates statistical significance with $p<0.05$.

aMann-Whitney test, $p<0.05$.

${ }^{b} \chi^{2}, p<0.05$

value $89 \%$, Figure 4). $\mathrm{PaO}_{2} / \mathrm{FiO}_{2}$ ratio at $6 \mathrm{~h}$ after extubation did not demonstrate any predictive ability for postoperative complications $(\mathrm{AUC}=0.543 ; p=0.67)$.

\section{DISCUSSION}

Our study has shown that IPI can provide important information about respiratory and hemodynamic status of the cardiosurgical patient, especially during the postextubation period.

In our study, we observed difficulties in registration of the IPI value after admission to the ICU in one patient from 40 enrolled into the study; this problem can be explained by decreased perfusion, leading to low $\mathrm{SpO}_{2}$ signal. Low perfusion as well as 


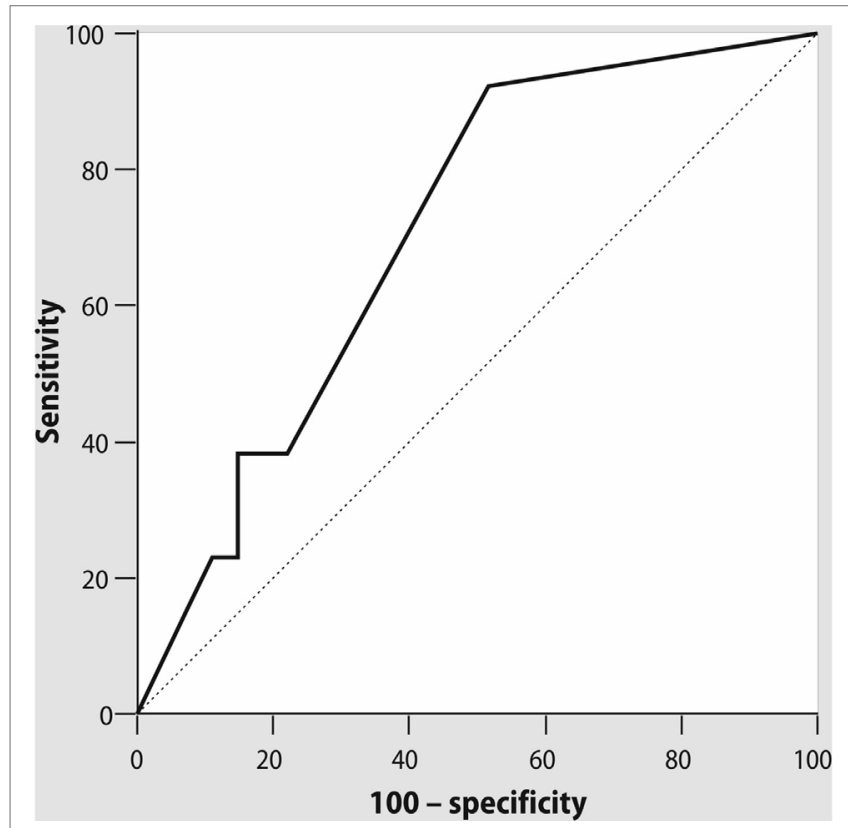

FIGURE 4 | ROC curve for Integrated Pulmonary Index (IPI), measured at $6 \mathrm{~h}$ after tracheal extubation, and early postoperative complications. $\mathrm{A} \cup \mathrm{C}=0.71$; $p=0.04$, cutoff point of $\mathrm{IPI} \leq 9$ with sensitivity $92 \%$ and specificity $48 \%$, positive predictive value $57 \%$, negative predictive value $89 \%$.

motion artifacts are the well-known limitations of pulse oximetry observed in the early postoperative period after cardiac surgery (19).

After admission to the ICU, the number of patients with compromised respiratory function according to their $\mathrm{PaO}_{2} / \mathrm{FiO}_{2}$ values (63\%) was higher than the number of patients requiring attention according to the IPI values (5\%). During controlled mechanical ventilation, several components of IPI like respiratory rate, $\mathrm{SpO}_{2}$, and $\mathrm{PetCO}_{2}$, are determined mainly by the operator-depending settings of the ventilator that may not reflect the complex respiratory status. The association of IPI, measured after admission to the ICU, with cardiac index and $\mathrm{ScvO}_{2}$, observed in our study can be explained by the relationship between cardiac output, $\mathrm{PetCO}_{2}$, and oxygen transport (20). Although the described correlations were weak that can be caused by dependence of end-tidal $\mathrm{CO}_{2}$ not only from cardiac output but also from ventilation, metabolism, and other factors, our findings are consistent with other investigations in this field. In several studies, authors demonstrated that PetCO $\mathrm{C}_{2}$ and cardiac output had a positive association in different categories of patients (21-23). Thus, Baraka and colleagues have shown that cardiac output correlated with $\mathrm{PetCO}_{2}$ during partial cardiopulmonary bypass and following weaning from bypass (22). In this study, $\mathrm{PetCO}_{2}>30 \mathrm{mmHg}$ during partial bypass predicted an adequate cardiac output after perfusion. At the same time, $\mathrm{PetCO}_{2}<30 \mathrm{mmHg}$ may correctly denote a low cardiac output only in combination with low $\mathrm{ScvO}_{2}$ (22). This relationship between $\mathrm{PetCO}_{2}$ and cardiac function can be relevant not only for cardiac surgery; thus, Dunham and colleagues have found that a decline in $\mathrm{PetCO}_{2}$ correlates with decrease in noninvasive cardiac output in emergently intubated trauma patients
(23). Notably, the addition of pulse rate into the algorithm for calculation of IPI could improve the ability of this parameter to predict decreased cardiac output compared with $\mathrm{PetCO}_{2}$ alone. However, our ROC analysis has shown equal AUC to predict $\mathrm{CI}<2.5 \mathrm{~L} / \mathrm{min} / \mathrm{m}^{2}$ both for IPI $<8$ and for $\mathrm{PetCO}_{2}<30 \mathrm{mmHg}$. The possible explanation for this finding could be that the heart rate is just one of the determinants of cardiac output, thus PetCO alone may have similar accuracy with IPI in predicting cardiac output after OPCAB.

Notably, reduced IPI values during controlled mechanical ventilation observed in our study can be explained by decreased PetCO $\mathrm{O}_{2}$ levels. During spontaneous breathing with ambient air $\left(\mathrm{FiO}_{2} 21 \%\right)$, suboptimal IPI was also associated with decreased $\mathrm{SpO}_{2}$ values and increased pulse rate, aiming to maintain adequate cardiac output and oxygen delivery. We suppose that, summarizing the key cardiovascular and respiratory parameters, IPI can be a useful tool for postoperative assessment of patient in addition to $\mathrm{PaO}_{2} / \mathrm{FiO}_{2}$ ratio, which has a limited value due to dependence on $\mathrm{FiO}_{2}$ (24) This can explain the stable values of $\mathrm{PaO}_{2} / \mathrm{FiO}_{2}$ with simultaneous reduction of $\mathrm{SpO}_{2}$ and IPI after extubation while breathing with ambient air. It is important to mention that the measurement of IPI does not replace postoperative blood gases but it can potentially reduce the number of blood gas samples, is continuous as compared to discrete blood gases and can serve as a "monitoring bridge" after discontinuation of mechanical ventilation and invasive monitoring.

The association of suboptimal IPI values with preoperative EuroScore and ejection fraction before and after intervention demonstrates the relationship of IPI and severity of cardiac comorbidities. Several studies have shown that decreased ejection fraction after cardiac surgery may be associated with risk of sepsis, postoperative respiratory failure and prolonged mechanical ventilation $(25,26)$. Thus, the reduction of IPI after cardiac surgery can detect patients who require more complex hemodynamic monitoring and optimization including fluids, diuretics, inotrope/vasopressor support, and other therapies.

Association between IPI value $\leq 9$, recorded at $6 \mathrm{~h}$ after extubation and the incidence of early complications after OPCAB seems to be relevant for prediction of the course of postoperative period. We did not find in other studies the data about the opportunity of IPI to predict the course of postoperative period, although IPI was effective in detection of clinically significant events, such as hypoxia or bradypnea, during the intraoperative period $(16,17)$. The complications observed during our study (predominantly, atrial fibrillation and respiratory failure) are accompanied by changes in respiratory and hemodynamic status of the patient. The patients after cardiac surgery can have a higher alert threshold of IPI as compared to other settings where the attention is required when IPI is $\leq 7$. The diagnostic capabilities of IPI need further validation and studies including the assessment of IPI as a marker for the safe transfer from ICU.

\section{Study Limitations}

Our findings have a limitation due to relatively small sample size. In addition, all the patients from our study received bisoprolol postoperatively that may influence the heart rate, as well as the IPI value. 


\section{CONCLUSION}

Integrated pulmonary index is associated with changes in cardiac output and may predict the postoperative complications during the discontinuation from mechanical ventilation and in the early postextubation period after OPCAB. This index may be a valuable adjunct to the routine monitoring during spontaneous breathing, but not during controlled mechanical ventilation.

\section{ETHICS STATEMENT}

This study was carried out in accordance with the recommendations of the ethics committee of the Northern State Medical University (Arkhangelsk, Russian Federation). All subjects gave written informed consent in accordance with the Declaration of Helsinki. The protocol was approved by the ethics committee of

\section{REFERENCES}

1. Ng CS, Wan S, Yim AP, Arifi AA. Pulmonary dysfunction after cardiac surgery. Chest (2002) 4:1269-77. doi:10.1378/chest.121.4.1269

2. Weissman C. Pulmonary complications after cardiac surgery. Semin Cardiothorac Vasc Anesth (2004) 8:185-211.doi:10.1177/108925320400800303

3. Forouzannia SK, Abdollahi MH, Mirhosseini SJ, Hadadzadeh M, Hosseini H, Moshtaghion SH, et al. Perioperative predictors and clinical outcome in early and late ICU discharge after off-pump coronary artery bypass surgery. Acta Med Iran (2011) 49:307-9.

4. Ho CH, Chen YC, Chu CC, Wang JJ, Liao KM. Postoperative complications after coronary artery bypass grafting in patients with chronic obstructive pulmonary disease. Medicine (Baltimore) (2016) 95:1-5. doi:10.1097/ MD.0000000000002926

5. Vakili M, Shirani S, Paknejad O, Yousefshahi F. Acute respiratory distress syndrome diagnosis after coronary artery bypass: comparison between diagnostic criteria and clinical picture. Acta Med Iran (2015) 53:51-6.

6. Vincent JL, Rhodes A, Perel A, Martin GS, Della Roca G, Vallet B, et al. Clinical review: update on hemodynamic monitoring-a consensus of 16 . Crit Care (2011) 15:1-8. doi:10.1186/cc10291

7. Brochard L, Martin GS, Blanch L, Pelosi P, Belda FJ, Jubran A, et al. Clinical review: respiratory monitoring in the ICU - a consensus of 16. Crit Care (2012) 16:1-14. doi:10.1186/cc11146

8. Heinze H, Sedemund-Adib B, Heringlake M, Meier T, Eichler W. Relationship between functional residual capacity, respiratory compliance, and oxygenation in patients ventilated after cardiac surgery. Respir Care (2010) 55:589-94.

9. MacNaughton PD. Assessement of lung function in the ventilated patients. Intensive Care Med (1997) 8:810-8. doi:10.1007/s001340050417

10. Technology Subcommittee of the Working Group on Critical Care, Ontario Ministry of Health. Noninvasive blood gas monitoring: a review for use in the adult critical care unit. CMAJ (1992) 146:703-12.

11. Alam N, Hobbelink EL, Tienhoven AJ. The impact of the use of the early warning score (EARLY WARNING SYSTEMS) on patient outcomes: a systematic review. Resuscitation (2014) 85:587-94.doi:10.1016/j.resuscitation.2014.01.013

12. Dawes TR, Cheek E, Bewick V, Dennis M, Duckitt RW, Walker J, et al. Introduction of an electronic physiological early warning system: effects on mortality and length of stay. Br J Anaesth (2014) 4:603-9. doi:10.1093/bja/aeu107

13. Kyriacos U, Jelsma J, James M, Jordan S. Early warning scoring systems versus standard observations charts for wards in South Africa: a cluster randomized controlled trial. Trials (2015) 16:103-18. doi:10.1186/s13063-015-0624-2

14. Ronen M, Weissbrod R, Overdyk FJ, Ajizian S. Smart respiratory monitoring: clinical development and validation of the IPI ${ }^{\mathrm{TM}}$ (integrated pulmonary index) algorithm. J Clin Monit Comput (2017) 31:435-42. doi:10.1007/ s10877-016-9851-7

15. Berkenstadt H, Ben-Menachem E, Herman A, Dach R. An evaluation of the integrated pulmonary index (IPI) for the detection of respiratory events the Northern State Medical University (Arkhangelsk, Russian Federation).

\section{AUTHOR CONTRIBUTIONS}

All authors had contributed equally.

\section{ACKNOWLEDGMENTS}

The authors thank the personnel of the cardiosurgical ICU, City Hospital \#1 of Arkhangelsk, for their kind assistance during the conduct of the investigation.

\section{FUNDING}

The study has received the research grant from Medtronic (Boulder, CO, USA).

in sedated patients undergoing colonoscopy. J Clin Monit Comput (2012) 26:177-81. doi:10.1007/s10877-012-9357-x

16. Garah J, Adiv OE, Rosen I, Shaoul R. The value of integrated pulmonary index (IPI) monitoring during endoscopies in children. J Clin Monit Comput (2015) 29:773-8. doi:10.1007/s10877-015-9665-Z

17. Sabbatani P, Mantovan R. Electrical cardioversion of atrial fibrillation: evaluation of sedation safety with midazolam by means of $\mathrm{EtCO}_{2}$ and IPI algorithm analysis. Int J Cardiol (2013) 169:430-2. doi:10.1016/j.ijcard.2013.10.015

18. Karbing DS, Rees SE, Jaffe MB. Journal of clinical monitoring and computing 2015 end of year summary: respiration. J Clin Monit Comput (2016) 30:7-12. doi:10.1007/s10877-015-9820-6

19. Nitzan M, Romem A, Koppel R. Pulse oximetry: fundamentals and technology update. Med Devices (Auckl) (2014) 7:231-9. doi:10.2147/MDER.S47319

20. Isserles SA, Breen $\mathrm{PH}$. Can changes in end-tidal $\mathrm{PCO}_{2}$ measure changes in cardiac output? Anesth Analg (1991) 6:808-14.

21. Whitaker DK, Benson JP. Capnography standards for outside the operating room. Curr Opin Anaesthesiol (2016) 29(4):485-92. doi:10.1097/ ACO.0000000000000355

22. Baraka AS, Aouad MT, Jalbout MI, Kaddoum RN, Khatib MF, Haroun-Bizri ST. End-tidal $\mathrm{CO}_{2}$ for prediction of cardiac output following weaning from cardiopulmonary bypass. J Extra Corpor Technol (2004) 36:255-7.

23. Dunham CM, Chirichella TJ, Gruber BS, Ferrari JP, Martin JA, Luchs BA, et al. In emergently ventilated trauma patients, low end-tidal $\mathrm{CO}_{2}$ and low cardiac output are associated and correlate with hemodynamic instability, hemorrhage, abnormal pupils, and death. BMC Anesthesiol (2013) 13:20-8. doi:10.1186/1471-2253-13-20

24. Karbing DS, Kjaergaard S, Smith BW, Espersen K, Allerød C, Andreassen S, et al. Variation in the $\mathrm{PaO}_{2} / \mathrm{FiO}_{2}$ ratio with $\mathrm{FiO}_{2}$ : mathematical and experimental description, and clinical relevance. Crit Care (2007) 11:R118. doi:10.1186/cc5697

25. Cohen AJ, Katz MG, Frenkel G, Medalion B, Geva D, Schachner A. Morbid results of prolonged intubation after coronary artery bypass surgery. Chest (2000) 6:1724-31. doi:10.1378/chest.118.6.1724

26. Topkara VK, Cheema FH, Kesavaramanujam S, Mercando ML, Cheema AF, Namerow PB, et al. Coronary artery bypass grafting in patients with low ejection fraction. Circulation (2005) 112:1344-50. doi:10.1161/ CIRCULATIONAHA.104.526277

Conflict of Interest Statement: The study has received the research grant from Medtronic (Boulder, CO, USA). The authors declare that the research was conducted in the absence of any other commercial or financial relationships that could be construed as a potential conflict of interest.

Copyright (c) 2017 Fot, Izotova, Yudina, Smetkin, Kuzkov and Kirov. This is an open-access article distributed under the terms of the Creative Commons Attribution License (CC BY). The use, distribution or reproduction in other forums is permitted, provided the original author(s) or licensor are credited and that the original publication in this journal is cited, in accordance with accepted academic practice. No use, distribution or reproduction is permitted which does not comply with these terms. 